\title{
Microsporogenesis and Induction of Unreduced Pollen with High Temperatures in Rubber Tree Clone RRIM 600
}

\author{
Peng-Qiang Yao ${ }^{1,2}$, Guo-Hua Li ${ }^{3}$, Qing-Yi Long ${ }^{3}$, Li-Gang He ${ }^{3}$ and Xiang-Yang Kang ${ }^{1,2, *}$ \\ 1 Beijing Advanced Innovation Center for Tree Breeding by Molecular Design, National Engineering \\ Laboratory for Tree Breeding, College of Biological Sciences and Technology, Beijing Forestry University, \\ No. 35, Qinghua East Road, Beijing 100083, China; yaopengqiang1988@163.com \\ 2 National Engineering Laboratory for Tree Breeding, Key Laboratory of Genetics and Breeding in Forest Trees \\ and Ornamental Plants, Ministry of Education, Beijing Laboratory of Urban and Rural Ecological \\ Environment, College of Biological Sciences and Technology, Beijing Forestry University, No. 35, \\ Qinghua East Road, Beijing 100083, China \\ 3 Tropic Crops Science Research Institute of Yunnan Province, Yunnan 666100, China; \\ 13708818917@139.com (G.-H.L.); lqingyi@163.com (Q.-Y.L.); ynhlg@163.com (L.-G.H.) \\ * Correspondence: kangxy@bjfu.edu.cn; Tel.: +86-10-6233-6168
}

Academic Editors: Jarmo K. Holopainen and Timothy A. Martin

Received: 11 February 2017; Accepted: 27 April 2017; Published: 2 May 2017

\begin{abstract}
In order to induce unreduced pollens, microsporogenesis and male flower bud (MFB) development were compared in rubber tree clone RRIM 600. We observed strong asynchronism in different MFBs in an inflorescence. Asynchronism of microsporogenesis in different microsporangiums from a MFB was also observed. The relationship between microsporogenesis and external morphology was examined, which was used to estimate microsporogenesis stages of MFBs. Unreduced pollen was successfully induced by high temperature exposure in this study, with the highest production ratio of about $20.17 \%$ at $44{ }^{\circ} \mathrm{C}$. Our findings showed that diplotene to metaphase I may be the most effective stage for unreduced pollen induction, and $42-44^{\circ} \mathrm{C}$ may be the suitable treatment temperature in rubber trees. Thus, microsporogenesis of MFBs has been elucidated in detail in the rubber tree clone RRIM 600 and will provide a reference for future breeding studies of rubber trees.
\end{abstract}

Keywords: rubber tree; microsporogenesis; high temperature; unreduced pollens

\section{Introduction}

The breeding of rubber trees dates from the 20th century. The exclusive objective of rubber tree breeding is to improve the yield of dry rubber (cis-1,4-polyisoprene), which is one of the most important polymers naturally produced by plants because it is a strategic raw material used in many products [1]. Polyploid breeding is a powerful and commonly applied strategy to produce altered genotypes for breeding purpose [2,3].

New rubber tree cultivars, Yunyan 77-2 and Yunyan 77-4, were discovered and confirmed as triploids, which have been extensively planted in Yunnan, China [4]. Some reports have shown that these triploids had relatively high rubber yields and good cold resistance [5,6], representing good breeding value in rubber tree development. Triploid can be induced by crossing tetraploid with diploid, or by combining unreduced (2n) gametes with reduced (n) gametes [7,8]. At present, no rubber tree tetraploids in the wild have been reported. Obviously, using the combining unreduced gametes with reduced gametes to obtain triploid would be a promising method in rubber tree polyploid breeding. 
Yunyan 77-2 and Yunyan 77-4 both were selected from GT 1 (Gondang Tapen, Indonesia) $\times$ PR 107 (Profestation voor Rubber, Indonesia) [9,10]. Yao et al. [11] has proved that rubber tree clone GT 1 is able to produce $2 \mathrm{n}$ megagametophyte spontaneously. At present, no unreduced pollen has been reported in rubber trees. In natural conditions, unreduced pollen has been discovered in many trees such as poplar, conifer, Chinese jujube, and Japanese persimmons [12-15]. Many efforts have also been made to induce unreduced pollen in many trees such as Eucalyptus, Eucommia ulmoides, and Ginkgo biloba [16-18]. There are no efforts of unreduced pollen induction in rubber trees. Further, the production of unreduced gametes by chromosome doubling during meiosis is helpful for genetic analysis and to facilitate the development of advanced germplasm in rubber trees.

The main factors affecting the induction of unreduced gametes are treatment period, mutagenic agents, and treatment duration. Mutagenic agent like high temperature has been applied to induce unreduced pollens in trees like Populus and Eucommia ulmoides [17,19]. Kang et al. [19] reported that the highest rate of $2 \mathrm{n}$ pollens can reach up to $87.6 \%$ with high temperature exposure in Populus tomentosa $\times$ P. Bolleana. Mao et al. [17] reported that exceeding $40 \%$ of $2 n$ pollen could be obtained by high temperature treatment in Eucommia ulmoides. The estimation of treatment stages is a critical point for unreduced gametes induction [3]. In Populus, water culture period and flower external morphology were used to estimate PMCs (pollen mother cells) development [19]. Mao et al. [17] observed a significant correlation between the male meiotic stage and mean diameter of male buds in Eucommia ulmoides. Yang and Kang [20] reported the relationship between microsporogenesis development and flower bud diameter growth in Eucalyptus urophylla $\times$ Eucalyptus tereticornis. However, these conditions are poorly understood in rubber trees, which could be a potential obstacle to rubber trees polyploidizing induction.

In this study, the rubber tree clone RRIM 600 (Rubber Research Institute of Malaysia) was used as material which was selected and bred from Tjir 1 (Tjirandji, Indonesia) $\times$ PB 86 (Prang Besar Rubber Estate) by the Rubber Research Institute of Malaysia [21,22]. It is the major variety cultivated on plantations in many countries [23]. This clone exhibits vigorous root development, high rubber latex content, and an abundance of both male and female flowers during the flowering period. The objective of this study was to investigate the relationship between microsporogenesis and MFB (male flower bud) development in rubber tree clone RRIM 600 which will serve as a reference in other rubber tree clones. This relationship can then be used to guide unreduced pollen induction for further breeding research.

\section{Materials and Methods}

\subsection{Plant Materials}

This study was performed with seven-year-old robust trees of the cultivar rubber tree clone RRIM $600(2 n=2 x=36)$, located in the Tropic Crops Science Research Institute of Yunnan Province, China.

\subsection{Morphological and Cytological Observations of MFBs}

For a new leaf canopy, microsporogenesis was easily observed in MFBs when petiole growth slowed, the leaf area increased rapidly, and the leaf color changed from yellowish-brown to light green (Figure 1). In this period, inflorescences could be chosen as a good material for microsporogenesis observation.

Each inflorescence included many sub-inflorescences. The positions of male and female flower buds are shown in Figure 2a. Generally, female buds were located at the top of inflorescence and sub-inflorescence, and ranged in number from two or more in different inflorescences. The rest were MFBs, which were located in different-order lateral branches. The MFBs on the first-order lateral branches (first-order MFBs) in every sub-inflorescence were numbered with increasing Arabic serial numbers from the bottom to the top according to their location (Figure 2a,b). Other smaller-order lateral male flower buds were not numbered due to their enormous numbers, with some withering and falling in the later stages of inflorescence development. 




Figure 1. The suitable inflorescence material for microsporogenesis observation. Arrows show the male flower buds.

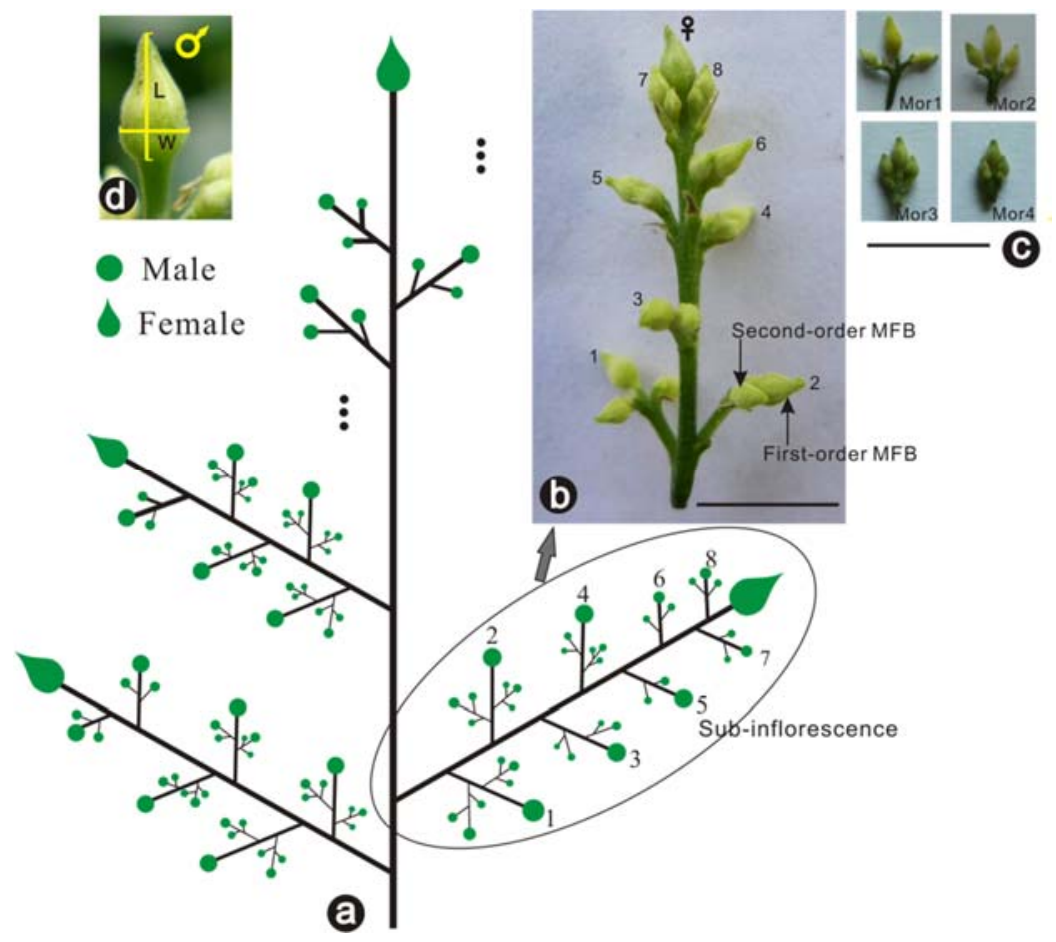

Figure 2. Flower bud locations in one inflorescence. (a) The MFBs on first-order lateral branches were numbered. Second-order MFBs were not numbered; third-order lateral branch MFBs may or may not have formed; (b) External morphological characteristics of MFBs in one sub-inflorescence (scale bar = $5 \mathrm{~mm}$ ); (c) External morphological characteristics of different MFBs (scale bar = $5 \mathrm{~mm}$ ); (d) Length (L) and width (W) of MFB.

The ontogeny of MFBs was divided into four periods based on a series of morphological changes (Figure 2b,c). At morphology 1, second-order MFBs were obviously separated from their first-order MFBs, and the size of first-order MFBs was about 1.5-fold or smaller than their second-order MFBs (Figure 2b MFB 1; Figure 2c Mor1). At morphology 2, second-order MFBs were slightly separated from their first-order MFBs, and the size of first-order MFBs were about 2-fold of their second-order MFBs (Figure 2b MFBs 2 and 3; Figure 2c Mor2). In morphology 3, the size of first-order MFBs were 2-3-fold of their second-order MFBs, with external characteristics of being close to each other (Figure 2b MFBs 
4, 5, and 6; Figure 2c Mor3). In morphology 4, the size of first-order MFBs were about 3-fold or bigger than their second-order MFBs and they were tightly close to each other (Figure 2b MFBs 7 and 8; Figure 2c Mor4).

Different sizes of inflorescences were gathered and fixed immediately in Carnoy's solution (3:1 ethanol/acetic acid) for $24 \mathrm{~h}$ at $4{ }^{\circ} \mathrm{C}$, and then transferred to $70 \%$ ethanol at $4{ }^{\circ} \mathrm{C}$ for long-term storage before observation. The length and width of first-order MFBs were measured with Vernier calipers; the length of the pedicel was excluded, and the diameter was used as the width (Figure 1d). Then, PMCs were pressed out of the anthers and squashed in $2 \%$ acetocarmine on microscope slides to observe microsporogenesis; some were dehydrated in alcohol, embedded in paraffin, and cut into sections (thickness: $8 \mu \mathrm{m}$ ). These sections were then stained with iron hematoxylin before observation.

\subsection{High-Temperature Treatment}

Based on the results of morphological and cytological observations, microsporogenesis of first-order MFBs were initially estimated by morphological observation. In one or two sub-inflorescences, some MFBs were made into slides with acetocarmine staining to definitively determine the development stage. These sub-inflorescences were used as markers to estimate others with similar flower development morphological characteristics. Then, MFBs at different stages of development were exposed to temperatures of $40{ }^{\circ} \mathrm{C}, 42{ }^{\circ} \mathrm{C}, 44^{\circ} \mathrm{C}$, and $46^{\circ} \mathrm{C}$, respectively, for $4 \mathrm{~h}$ using a high-temperature treatment machine (China patent no. ZL200610113448.X) (Figure 3). Three repetitions were conducted per temperature, and all treatments included at least two sub-inflorescences with similar external morphology and developmental stages. Data regarding treatment and locations of MFBs were recorded. Untreated MFBs were used as controls.

Pollen grains were used to make slides for microscopic analyses. Five fields were observed randomly for each slide, and more than ten slides were made for each treatment. Pollen grains were observed by acetocarmine or carbol fuchsin staining under a microscope.

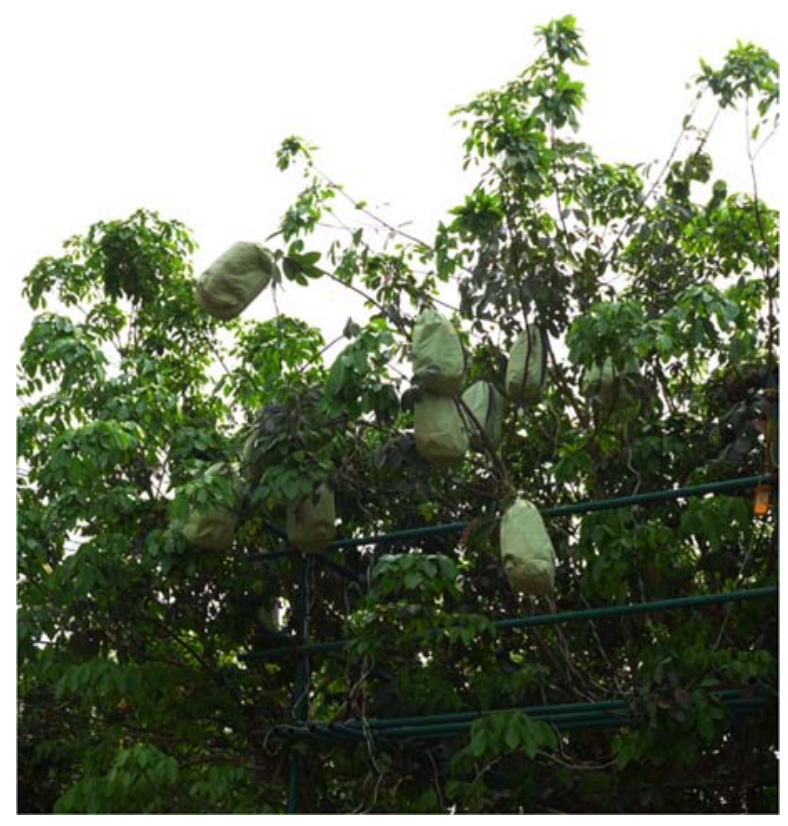

Figure 3. High temperature treatment with a heating device to Hevea brasiliensis MFBs during microsporogenesis induce microspore chromosome doubling.

\subsection{Statistics and Data Analysis}

All preparations were observed using an Olympus BX51 microscope with an attached DP70 digital camera (Olympus, Tokyo, Japan). The images were optimized for contrast and brightness using 
Adobe Photoshop CS6 (Adobe, San Francisco, CA, USA). Sketches of inflorescences were made using CorelDRAW X4 (Corel, Ottawa, ON, Canada). Meiotic developmental stages and sizes of the MFBs were recorded and analyzed. The relationship between percentage of unreduced pollen production and the proportion of each PMC's developmental stage, each of the temperatures was analyzed by the Student Newman Keuls Test (S-N-K) method. It is a multiple comparison method which is often used when comparing between different groups. The means of different groups will be divided into different columns if there are significant variations based on the comparison between any two numbers which belong to different groups, while the means of different groups will be located in the same column if there are no significant variations. All statistical analyses were performed using IBM SPSS Statistics 19 (IBM, Armonk, NY, USA).

\section{Results}

\subsection{Asynchronism of Microsporogenesis in Different Microsporangiums from the MFB}

Figure 4 shows an outline of normal microsporogenesis in rubber tree RRIM 600. In prophase I, the nucleolus changed from clear to very small or even disappeared, and the chromosomes were filamentous at the beginning then became very short and took on a punctiform appearance (Figure 4a-g, i.e., early leptotene to diakinesis). From metaphase I to telophase I, the autochromosomes separated from each other and moved to the two poles, and several nucleoli could be observed in one nucleus at the two poles (Figure 4h-1). From prophase II to telophase II, the sister chromatids separated from each other and arrived at their respective poles (Figure $4 \mathrm{~m}-\mathrm{q}$ ). In tetrad stage, a tetrahedral outline could be observed (Figure 4r).
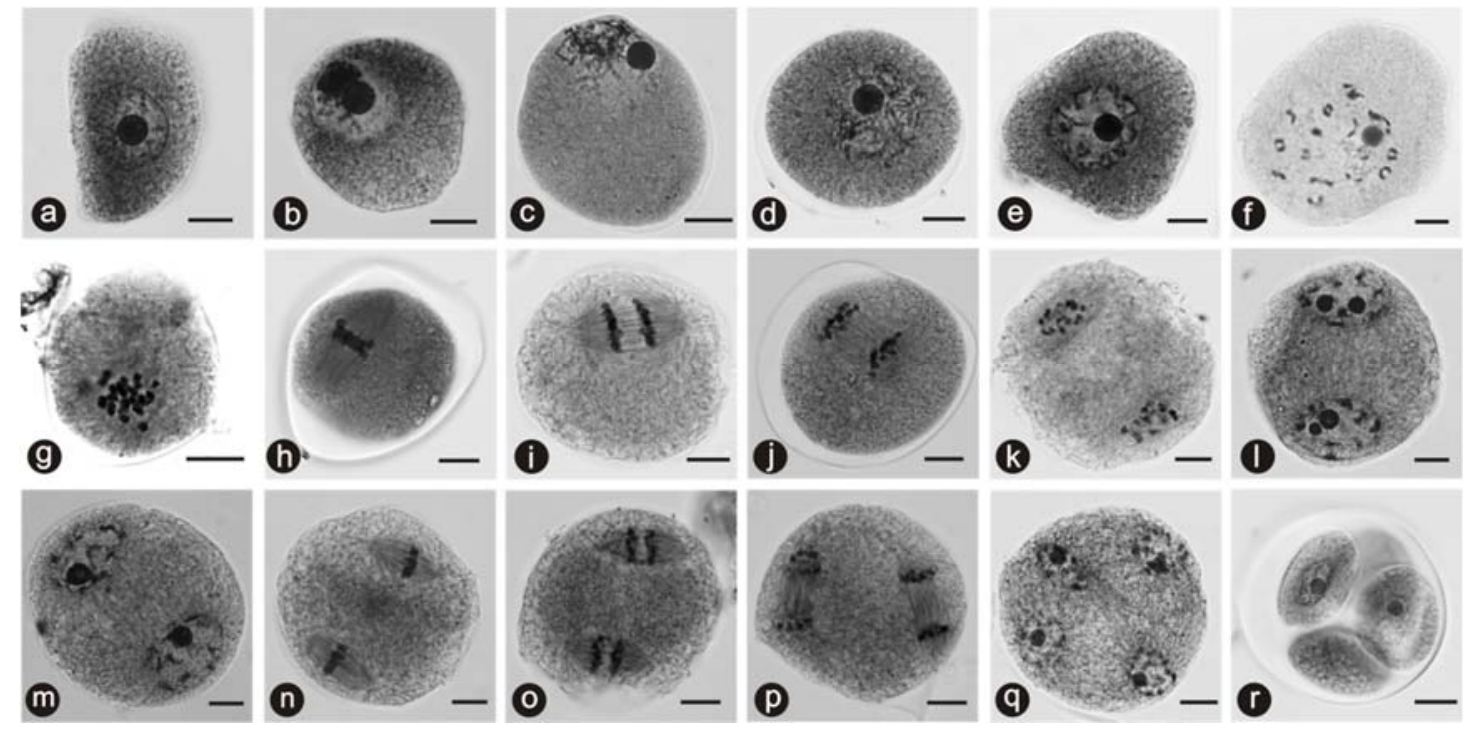

Figure 4. Microsporogenesis of rubber tree RRIM 600 (scale bar = $10 \mu \mathrm{m}$ ). (a) Early leptotene; (b,c) Late leptotene; (d) Pachytene; (e,f) Diplotene; (g) Diakinesis; (h) Metaphase I; (i-k) Anaphase I; (1) Telophase I; (m) Prophase II; (n) Metaphase II; (o,p) Anaphase II; (q) Telophase II; (r) Tetrad.

Multiple meiotic phases were observed in one MFB (Figure 5a; some cells in the metaphase II stage, and some in the tetrad stage). Asynchronism of microsporogenesis in different microsporangiums from a flower bud was observed (Figure $5 b$; diplotene in 'b1' microsporangium; metaphase I in 'b2' microsporangium, and telophase I in 'b3' microsporangium). Meiotic phases were nearly synchronous in the same microsporangium (Figure $5 \mathrm{c}$ later leptotene; Figure $5 \mathrm{~d}$ metaphase I; Figure 5e telophase II; Figure $5 \mathrm{f}$ mononucleate in the middle of microspore-these four microsporangiums were not from the same single MFB). The results revealed that microsporogenesis asynchronism of one MFB mainly 
resulted from differences in microsporangiums. We determined one microsporogenesis stage as one MFB development stage based on which cell stage was present in the largest proportion.

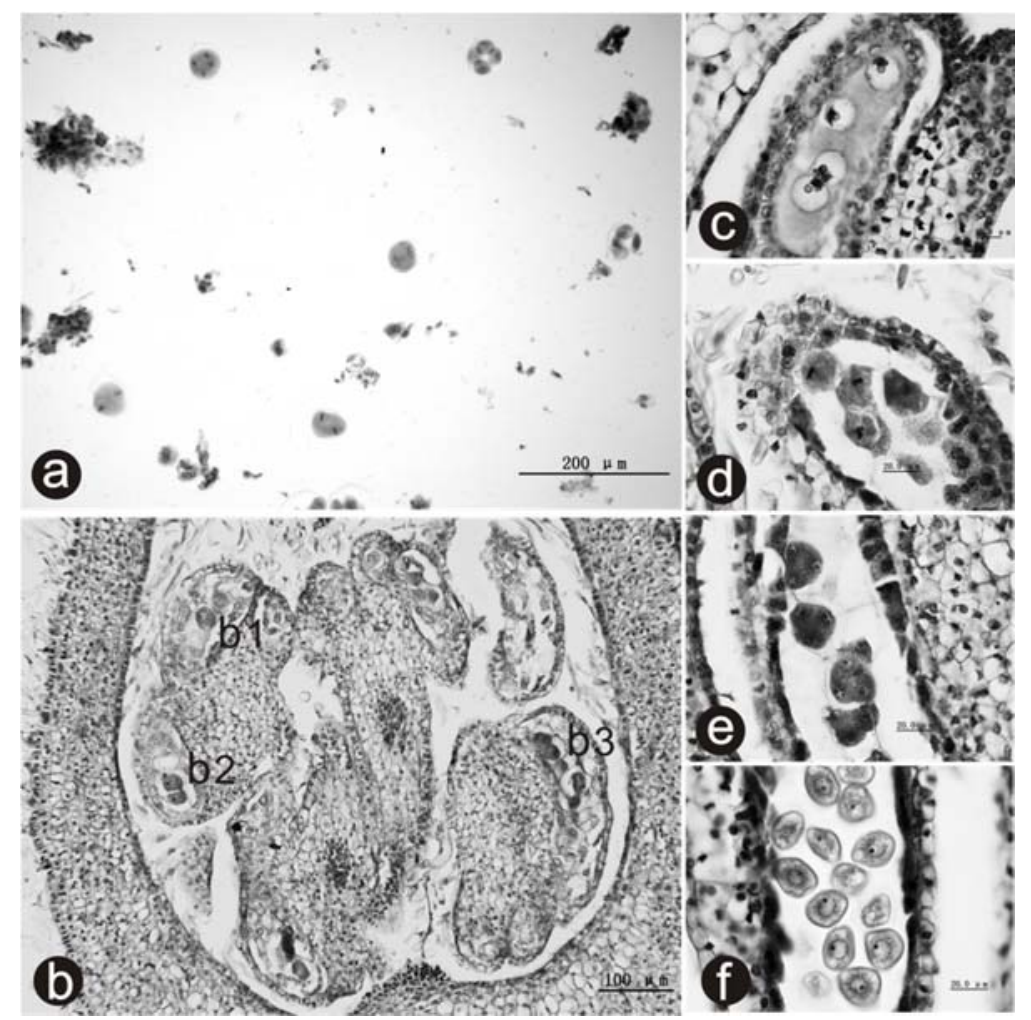

Figure 5. Microsporogenesis in anthers. (a) Asynchronism meiosis development in one MFB (scale bar $=200 \mu \mathrm{m})$; (b) Asynchronism meiosis development in different microsporangiums of one MFB (scale bar = $100 \mu \mathrm{m}$; b1, diplotene; b2, metaphase I; b3, telophase I); (c) Late leptotene in a microsporangium (scale bar $=10 \mu \mathrm{m})$; $(\mathrm{d})$ Metaphase I in a microsporangium (scale bar $=20 \mu \mathrm{m}$ ); (e) Telophase II in a microsporangium (scale bar $=20 \mu \mathrm{m}$ ); (f) microspore in a microsporangium (scale bar $=20 \mu \mathrm{m})$.

\subsection{Relationship between Microsporogenesis and Morphological Characteristics of MFBs}

The relationship between microsporogenesis and size of MFBs is shown in Table 1. Some meiotic stages were rarely identified (telophase I, prophase II, and metaphase II), whereas other stages were common (e.g., late leptotene, pachytene, tetrad, and uninucleate in the middle of the gametophyte).

Our results revealed only slight changes in MFB width at microsporogenesis $(<0.1 \mathrm{~mm})$. Changes in MFB length from pachytene stage to tetrad stage were also slight, especially between two adjacent stages $(<0.1 \mathrm{~mm})$. Comparison analysis showed that pachytene to tetrad stage could not be subdivided according to changes in MFB size. Therefore, microsporogenesis of MFB was most possible in pachytene to tetrad stages when its length changed from $1.63 \mathrm{~mm}$ to $1.83 \mathrm{~mm}$, and the width changed from $1.12 \mathrm{~mm}$ to $1.21 \mathrm{~mm}$.

The relationships between microsporogenesis and the external characteristics of MFBs were recorded (Table 2). At morphology 1, the representative microsporogenesis stage of first-order MFBs was microspore (91.8\%). At morphology 2, the main microsporogenesis stages of first-order MFBs were tetrad and microspore (41.39\% and 32.08\%, respectively). At morphology 3, most of the meiotic stages could be observed with higher ratios of diplotene to metaphase I (37.12\%) and anaphase I to telophase II (29.84\%). At morphology 4, PMCs began to undergo meiosis with representative stages from archesporial cells to early leptotene (42.16\%), and some had even undergone the stages from diplotene to metaphase I (9.31\%). 
Table 1. Relationship between microsporogenesis and MFB size.

\begin{tabular}{|c|c|c|c|}
\hline \multirow{2}{*}{ Microsporogenesis Stages } & \multicolumn{2}{|c|}{ Average \pm SE of MFBs (mm) } & \multirow{2}{*}{$\begin{array}{l}\text { Number of MFBs } \\
\text { Examined }\end{array}$} \\
\hline & Length & Width & \\
\hline Archesporial cell & $\leq 1.162 \pm 0.040$ & $\leq 0.916 \pm 0.016$ & 96 \\
\hline Early leptotene & $\overline{1} .346 \pm 0.011$ & $1.001 \pm 0.006$ & 192 \\
\hline Late leptotene & $1.497 \pm 0.008$ & $1.068 \pm 0.004$ & 248 \\
\hline Pachytene & $1.632 \pm 0.009$ & $1.123 \pm 0.005$ & 208 \\
\hline Diplotene & $1.708 \pm 0.018$ & $1.154 \pm 0.007$ & 132 \\
\hline Diakinesis & $1.678 \pm 0.023$ & $1.167 \pm 0.010$ & 108 \\
\hline Metaphase I & $1.695 \pm 0.026$ & $1.145 \pm 0.015$ & 86 \\
\hline Anaphase I & $1.723 \pm 0.024$ & $1.144 \pm 0.006$ & 92 \\
\hline Telophase I & $1.783 \pm 0.043$ & $1.150 \pm 0.032$ & 48 \\
\hline Prophase II & $1.723 \pm 0.029$ & $1.142 \pm 0.027$ & 30 \\
\hline Metaphase II & $1.704 \pm 0.043$ & $1.173 \pm 0.017$ & 52 \\
\hline Anaphase II & $1.736 \pm 0.038$ & $1.149 \pm 0.012$ & 90 \\
\hline Telophase II & $1.763 \pm 0.021$ & $1.180 \pm 0.010$ & 106 \\
\hline Tetrad & $1.830 \pm 0.009$ & $1.211 \pm 0.004$ & 290 \\
\hline Microspore & $\geq 1.957 \pm 0.011$ & $\geq 1.266 \pm 0.005$ & 228 \\
\hline
\end{tabular}

Table 2. Microsporogenesis at different MFB morphology stages in rubber tree clone RRIM 600.

\begin{tabular}{ccccc}
\hline \multirow{2}{*}{ Microsporogenesis Stages } & \multicolumn{4}{c}{ MFBs Stage (\%) } \\
\cline { 2 - 5 } & Morphology 1 & Morphology 2 & Morphology 3 & Morphology 4 \\
\hline Archesporial cell-early leptotene & - & - & 0.53 & 42.16 \\
Late leptotene & - & - & 8.53 & 32.11 \\
pachytene & - & - & 11.90 & 16.42 \\
Diplotene-metaphase I & - & 6.14 & 37.12 & 9.31 \\
Anaphase-telophase II & - & 20.40 & 29.84 & - \\
Tetrad & 8.20 & 41.39 & 12.08 & - \\
Microspore & 91.80 & 32.08 & - & 408 \\
\hline
\end{tabular}

\subsection{Production of Unreduced Pollen}

Monads, dyads, and triads were observed in MFBs after exposure to high temperature treatment (Figure 6), which were enclosed by callose. Monads correlated with bigger pollen $(n=4 x)$; and dyads correlated with $2 \mathrm{n}$ pollens. Triads correlated with one $2 \mathrm{n}$ pollen and two $\mathrm{n}$ pollens.

Different sizes of pollens were observed after high-temperature exposure (Figure 7). The diameter of pollen grains ranged from $39.32 \mu \mathrm{m}$ to $44.21 \mu \mathrm{m}(42.0 \pm 0.37 \mu \mathrm{m})$ in the control group. In the treatment group, we found large pollen grains generally ranging in size from $50.35 \mu \mathrm{m}$ to $67.54 \mu \mathrm{m}$ $(58.0 \pm 0.47 \mu \mathrm{m})$ (Figure 7a). Some giant pollen grains $(>70 \mu \mathrm{m})$ were also observed (Figure 7c). These large pollen grains were considered to be unreduced, and could be easily distinguished from normal pollen grains. Sometimes, the unreduced pollen grains had four germ pores, in contrast to the three germ pores in normal pollen grains (Figure $7 \mathrm{~b}$ ). However, more often we observed a thick pollen wall without germ pores. 

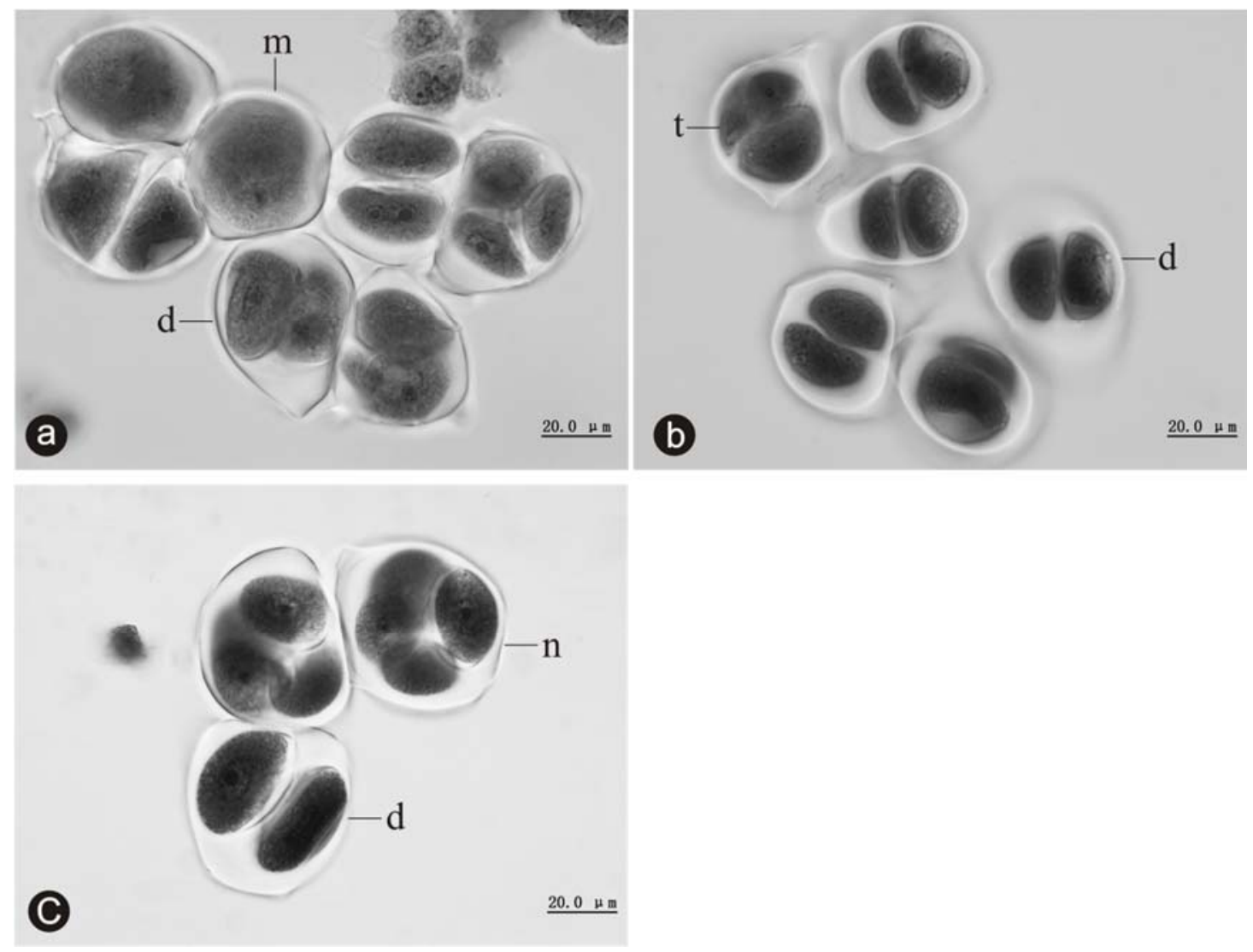

Figure 6. Unreduced pollen formation in rubber tree clone RRIM 600. (a) Monad (m) and dyad (d) $($ scale bar $=20 \mu \mathrm{m}) ;($ b $)$ Dyad $(\mathrm{d})$ and triad $(\mathrm{t})($ scale bar $=20 \mu \mathrm{m}) ;(\mathrm{c})$ Normal tetrad $(\mathrm{n})$ and dyad $(\mathrm{d})$ (scale bar $=20 \mu \mathrm{m})$.

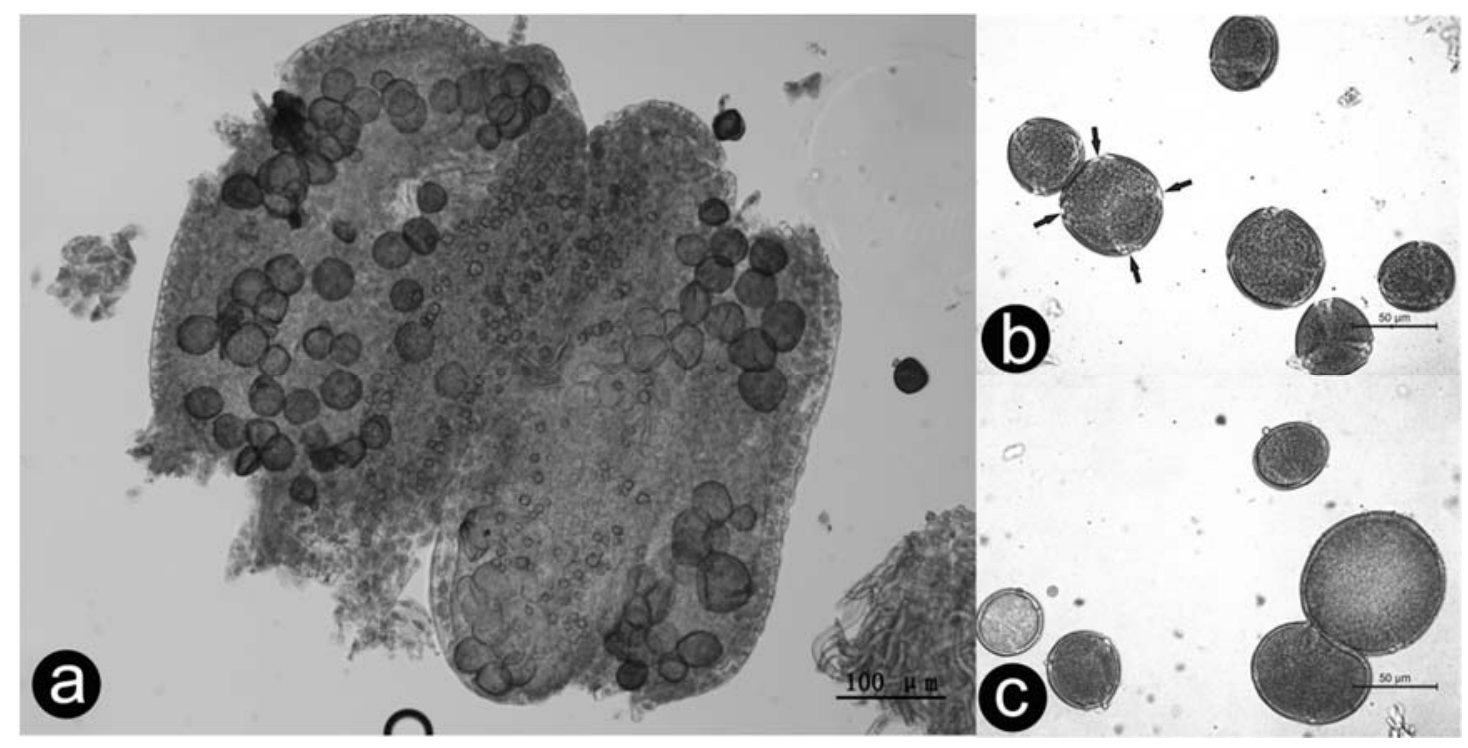

Figure 7. Unreduced and reduced pollen grains. (a) Different-sized pollen grains in anthers (scale bar $=100 \mu \mathrm{m})$; (b) Unreduced pollen with four germ pores, in contrast to the three germ pores in normal pollen (scale bar $=50 \mu \mathrm{m})$; (c) Giant pollen and reduced pollen (scale bar $=50 \mu \mathrm{m})$.

Table 3 presents the statistical results of unreduced pollens for different external characteristics of MFBs and different temperature exposures. The highest ratio of unreduced pollen grains was 
$20.17 \pm 2.90 \%$ with a treatment temperature of $44{ }^{\circ} \mathrm{C}$ for first-order MFBs at morphology 2. Unreduced pollen was not found in the control group (0). We obtained a lower ratio of unreduced pollen from first-order MFBs at other morphologies.

Table 3. Ratio of unreduced pollen for different external characteristics of MFBs and under different temperature exposures.

\begin{tabular}{cccccc}
\hline \multirow{2}{*}{$\begin{array}{c}\text { Treatment } \\
\text { Temperature }\left({ }^{\circ} \mathbf{C}\right)\end{array}$} & \multicolumn{3}{c}{ Unreduced Pollen Ratio of Different MFBs (\%) } & \multirow{2}{*}{$\begin{array}{c}\text { Total Number of } \\
\text { MFBs Examined }\end{array}$} \\
\cline { 2 - 5 } & Morphology 1 & Morphology 2 & Morphology 3 & Morphology 4 & \\
\hline 40 & $0.25 \pm 0.10$ & $8.53 \pm 1.13$ & $12.21 \pm 2.52$ & $2.73 \pm 0.12$ & 124 \\
42 & $1.36 \pm 0.18$ & $11.48 \pm 2.39$ & $18.63 \pm 3.36$ & $4.15 \pm 0.21$ & 137 \\
44 & $0.57 \pm 0.26$ & $10.45 \pm 2.21$ & $20.17 \pm 2.90$ & $3.73 \pm 0.45$ & 120 \\
46 & $1.32 \pm 0.20$ & $7.52 \pm 2.23$ & $11.87 \pm 2.03$ & $2.56 \pm 0.22$ & 108 \\
control & 0 & 0 & 0 & 0 & 182 \\
\hline
\end{tabular}

Comparison analysis suggested that the ratio of unreduced pollen differed markedly between different male buds $(F=70.536, p=0.000)$ and different treatment temperatures $(F=9.305, p=0.000)$, and it was necessary to examine the effects of different MFBs and different temperatures by multiple comparison among means of different groups (Tables 4 and 5).

Table 4. Means comparison of unreduced pollen yield between any two different temperatures by Student Newman Keuls (S-N-K) comparison (significance level = 0.01).

\begin{tabular}{ccc}
\hline \multirow{2}{*}{ Temperature $\left({ }^{\circ} \mathbf{C}\right)$} & \multicolumn{2}{c}{ Subset $(\boldsymbol{\alpha = 0 . 0 1 )}$} \\
\cline { 2 - 3 } & $\mathbf{1}$ & $\mathbf{2}$ \\
\hline 40 & 5.0231 & - \\
46 & 5.4403 & - \\
42 & - & 8.5431 \\
44 & - & 8.0657 \\
Sig. & 0.272 & 0.281 \\
\hline
\end{tabular}

Table 5. Means comparison of unreduced pollen yield between any two different MFBs by S-N-K comparison analysis (Significance level $=0.01$ ).

\begin{tabular}{ccccc}
\hline \multirow{2}{*}{ Different MFBs } & \multicolumn{4}{c}{ Subset $(\boldsymbol{\alpha}=\mathbf{0 . 0 1})$} \\
\cline { 2 - 5 } & $\mathbf{1}$ & $\mathbf{2}$ & $\mathbf{3}$ & $\mathbf{4}$ \\
\hline Morphology 1 & 0.8201 & - & - & - \\
Morphology 2 & - & 8.4233 & - & - \\
Morphology 3 & - & - & 15.8203 & - \\
Morphology 4 & - & - & - & 3.1025 \\
Sig. & 1.000 & 1.000 & 1.000 & 1.000 \\
\hline
\end{tabular}

Treatment temperatures of $42{ }^{\circ} \mathrm{C}$ and $44{ }^{\circ} \mathrm{C}$ are located in the same column in Table 4 , suggesting that both temperatures had similar effects on induction of unreduced pollen in rubber tree clone RRIM $600(p=0.281>0.05)$; both were suitable temperatures that yielded higher values (8.5431 and 8.0657, respectively). Temperatures of $40{ }^{\circ} \mathrm{C}$ and $46^{\circ} \mathrm{C}$ are also in the same column in Table 4 , indicating that these temperatures (lower and higher than those described above) were probably unsuitable for induction of unreduced pollen, yielding lower values (5.0231 and 5.4403, respectively).

As shown in Table 5, MFBs of all different morphologies are in different columns $(p=1.000)$, indicating that the yield of unreduced pollen was markedly different between MFBs of different morphologies. The lower values in morphology 1 and morphology 4 (0.8201 and 3.1025, respectively) indicated a lower yield of unreduced pollen when they were chosen as materials. These observations also showed that early meiosis stages, such as archesporial cells, early leptotene, late leptotene, and 
even pachytene stages (MFBs in morphology 4) and late meiosis stages, such as tetrad or microspore stages (MFBs in morphology 1), were not suitable for treatment to induce unreduced pollen in rubber tree clone RRIM 600 by high-temperature exposure. The higher value (15.8203) for MFBs in morphology 3 indicated that these MFBs were suitable materials for induction of unreduced pollen.

In this study, high temperature as an effective mutagenic agent was used for unreduced pollen induction in rubber trees. The key technique of induction was to determine the suitable microsporogenesis stages which always correlate with external characteristics of MFBs. Asynchronism of microsporogenesis not only exists in different MFBs but also in different microsporangiums of a MFB. The suitable unreduced pollens induction condition was $42-44{ }^{\circ} \mathrm{C}$ high temperature exposure when the MFB was in morphology 3.

\section{Discussion}

High temperature is one common method for induction of $2 n$ gametes. As such, high temperature was used in Populus, with the highest efficiency of triploid production being $66.7 \%$ in Populus pseudo-simonii $\times$ Populus nigra 'Zheyin3\#' [24], and the highest efficiency of triploid production being $83.33 \%$ in Populus adenopoda [25]. High temperature was also used in Eucommia ulmoides, with $5.74 \%$ efficiency of triploid induction [26]. Our results confirmed that exposure to high temperature was an efficient mutagenic agent for induction of unreduced pollen in rubber trees. Different plants have different suitable high temperatures for the induction of unreduced pollen. In this study, temperatures of $42{ }^{\circ} \mathrm{C}$ and $44{ }^{\circ} \mathrm{C}$ were suitable for the induction of unreduced pollen, which were relatively high compared to the temperatures of $35.5^{\circ} \mathrm{C}$ for chili and $36{ }^{\circ} \mathrm{C}$ for Populus alba. $[27,28]$, indicating that tropical plants can endure higher temperatures due to the warmer growing environment. However, exposure to extremely high temperatures, such as $46{ }^{\circ} \mathrm{C}$ or higher, is harmful and always leads to the drying of branches, corresponding to poor production of unreduced pollen.

In this study, we obtained different ratios of unreduced pollens after different morphological MFBs were exposed to high temperature. Determination of effective stages for treatment is important to induce unreduced gametes. In this study, higher yields of unreduced pollen were obtained in morphology 3 MFBs, which have higher ratios of diplotene to metaphase I (37.12\%) and anaphase I to telophase II (29.84\%) (Table 2), and unreduced pollen could also be obtained in MFBs of morphology 2 and morphology 4 , both of which have certain ratios of diplotene to metaphase I $(6.14 \%$ and $9.31 \%$, respectively; see Table 2), again confirming that diplotene to metaphase I is probably the most suitable period for induction of unreduced pollen. The results presented here are similar to those from previous studies of Populus and Eucalyptus [16,17,19]. In Populus, water culture period and flower external morphology were used to estimate PMCs development [19]. In Eucalyptus, flower bud diameter was used to estimate PMCs development [20]. However, in rubber trees the branches cannot be cultured in water and the male flower bud size changed relatively little. As such, it was a better method to use the external morphology relationship among different MFBs to estimate microsporogenesis which is the method that this study has described. In this study only one rubber tree clone RRIM 600 was used as material to study the relationship. The morphological indicators might be different in different genotypes. As such, it is necessary to check these relationships before readers conduct further studies or applications in different rubber tree clones.

Asynchronous microsporogenesis is one of the main reasons for the low ratio of unreduced pollen (the highest was $20.17 \pm 2.90 \%$ ) in this study. The developmental event of microsporogenesis is exquisitely timed and choreographed [29], and is generally considered synchronous in higher plants. In this study, strong asynchronism was observed in different MFBs of one inflorescence and asynchronism was also observed in different anthers of one MFB, as reported in E. urophylla $\times$ E. tereticornis [20]. However, asynchronism of microsporogenesis was observed not only in different anthers, but also in different microsporangiums of one anther in our study. This phenomenon is probably a mechanism of environmental adaptation $[20,30]$. 
Pollen grain size and shape are associated with sexual polyploidization. The diameter of $2 \mathrm{n}$ pollen was approximately 30\% larger than that of $\mathrm{n}$ pollen; this has been reported in Ipomoea batatas, Tulipa, Lilium, and Achillea borealis [31-35]. In some species, unreduced pollen is larger than $\mathrm{n}$ pollen by much more than $30 \%$, such as the giant pollen grains $(n=8 x)$ of $A$. borealis [35]. In this study, the diameter of normal pollen grains was about $42.0 \mu \mathrm{m}$, while that of unreduced pollen grains was about $58.0 \mu \mathrm{m}$; on average, the diameter of unreduced pollen grains was about 1.38 times that of $\mathrm{n}$ pollen grains, and some bigger pollen grains were also observed. These results suggest that treated male flower buds probably contain reduced pollen grains $(n=x), 2 n$ pollen grains $(n=2 x)$, and giant pollen grains, confirming that different mechanisms of unreduced pollen induction occurred by exposure to high temperatures. In some species, unreduced pollen can also be identified by its shape; for example, unreduced pollen grains are spherical in both lily and Eucalyptus, while normal pollen grains are elliptical and tetrahedral, respectively $[3,16]$. In A. borealis, reduced grains have three pores and are more triangular in shape, while unreduced grains typically have four pores and are round [35]. In rubber tree plants, both normal and unreduced pollen are round, but the number of germ pores can be used to distinguish between unreduced and normal pollen grains when they are obvious.

The long breeding cycle and larger size of the crop make the breeding process time consuming in rubber trees [36]. Hybridization and selection are still the main breeding methods, and the progress has been moving slowly in recent years [37]. Recently biotechnology was used in rubber tree breeding including in vitro culture and molecular genetics. However, they are meeting different obstacles and still under experimentation $[36,38,39]$. In polyploidy breeding, many previous efforts have been done in rubber trees, and the polyploids have been induced and reported. However, most of the induction polyploids were chimeras which need to be screened over several generations in order to acquire steady polyploid [40-42]. Further application of these polyploid was not reported. Although triploid clones Yunyan 77-2 and Yunyan 77-4 have been selected from the natural rubber trees population and were reported in 2009 by Li et al. [4], no efforts had been made to understand the mechanism of triploid until Yao et al. [11] reported that rubber tree clone GT 1 can produce 2 n megagametophyte spontaneously, which will provide reasonable guidance for polyploid induction using $2 n$ gametes.

The objective of unreduced pollen induction is to use these pollens to pollinate female gametes in order to produce polyploid offspring. In rubber tree, hand pollination is laborious because of the small size of the flowers. Average fruit-set is generally no more than $8 \%$ with normal pollen grains when hand pollination is carried out in Hevea breeding [43,44]. In this study, unreduced pollen, with a relatively low ratio may further result in low fruit-set of triploids. Kang et al. [45] reported that in Populus $2 \mathrm{n}$ pollen had less chance of fertilizing female gametes and was less competitive than normal pollen in fertilization. These reasons may result in low fruit-set of triploids when unreduced pollens were used in rubber tree breeding. Therefore, a large workforce would be required when unreduced pollen was used in future breeding of polyploid rubber trees. In recent years, utilization of unreduced female gametes to increase the incidence of polyploids has been proven to be a more effective approach $[24,25,46]$. Based on the results of this study, $2 n$ female gametes induction should be further exploited and applied in future polyploid breeding for rubber trees, and more related work needs to be done in future rubber tree research based on this study.

\section{Conclusions}

This study proved that high temperature can be used as an effective mutagenic agent to induce unreduced pollens in rubber trees. Microsporogenesis can be estimated by the size of MFBs and the external morphology relationship among different MFBs. This relationship should be specifically determined when it is used in other rubber tree clones. Asynchronism of microsporogenesis not only happened in different MFBs of an inflorescence, but also happened in different microsporangiums of a male flower bud, which is a main reason for the low ratio of unreduced pollens. Diplotene to metaphase I of microsporogenesis may be the most effective stage for unreduced pollen induction in rubber trees. 
Acknowledgments: This work was supported by the Special Found for Beijing Common Construction Project, Beijing Natural Science Foundation (5141001), and Sci-Tech Innovation System Construction for Tropical Crops Grant of Yunnan Province (391-1-4).

Author Contributions: Conceived and designed the experiments: X.-Y.K., P.-Q.Y., G.-H.L.; performed the experiments: P.-Q.Y., Q.-Y.L.; contributed materials/analysis tools: P.-Q.Y., G.-H.L., L.-G.H.; wrote the paper: X.-Y.K., P.-Q.Y.

Conflicts of Interest: The authors declare no conflict of interest.

\section{References}

1. Mooibroek, H.; Cornish, K. Alternative sources of natural rubber. Appl. Microbiol. Biotechnol. 2000, 53, 355-365. [CrossRef] [PubMed]

2. Dewitte, A.; Van Huylenbroeck, J.; Van Laere, K. Use of $2 n$ Gametes in Plant Breeding; InTech Open Access Publisher: Rijeka, Croatia, 2012; Available online: http://cdn.intechopen.com/pdfs/25553/InTech-Use_of_ 2n_gametes_in_plant_breeding.pdf (accessed on 10 June 2012).

3. Kang, X.Y.; Wang, J. Technology Study on Polyploidy Induction in Populus; Science Press: Beijing, China, 2010; pp. 7-56.

4. Li, H.B.; Zhou, T.Y.; Ning, L.Y.; Li, G.H. Cytological identification and breeding course of Hevea 'Yunyan 77-2' and 'Yunyan 77-4'. J. Trop. Subtrop. Bot. 2009, 17, 602-605.

5. Ao, S.C.; He, L.G.; Xiao, G.X.; Chen, J.B.; He, C.G. High yield and cold resistance Hevea of Yunyan 77-2 and Yunyan 77-4 selection and breeding. J. Yunnan Trop. Crop. Sci. Technol. 1998, 21, 3-8.

6. Li, M.Q. Physiological identification of cold resistance of Hevea Yunyan 77-2 and Yunyan 77-4. Trop. Agric. Sci. Technol. 2005, 28, 3-6.

7. Carputo, D.; Barone, A.; Frusciante, L. 2n gametes in the potato: Essential ingredients for breeding and germplasm transfer. Theor. Appl. Genet. 2000, 101, 805-813. [CrossRef]

8. Przybyla, A.; Behrend, A.; Bornhake, C.; Hohe, A. Breeding of polyploid heather (Calluna vulgaris). Euphytica 2014, 199, 273-282. [CrossRef]

9. Yang, L.Q. Forepart study on new varieties Yunyan 77-2 and Yunyan 77-4 of Hevea brasiliensis. J. Yunnan Trop. Crop. Sci. Technol. 2002, 25, 1-4.

10. Feng, S.P.; Li, W.G.; Huang, H.S.; Wang, J.Y.; Wu, C.T. Development, characterization and cross-species/genera transferability of EST-SSR markers for rubber tree (Hevea brasiliensis). Mol. Breed. 2009, 23, 87-97. [CrossRef]

11. Yao, P.Q.; Li, G.H.; Long, Q.Y.; He, L.G.; Kang, X.Y. Male parent identification of triploid rubber trees (Hevea brasiliensis) and the mechanism of $2 \mathrm{n}$ gametes formation. Forests 2016, 7, 301. [CrossRef]

12. Zhang, J.F.; Wei, Z.Z.; Li, D.; Li, B.L. Using SSR markers to study the mechanism of $2 \mathrm{n}$ pollen formation in Populus $\times$ euramericana (Dode) Guinier and P. $\times$ popularis. Ann. For. Sci. 2009, 66, 1-10. [CrossRef]

13. Kürschner, W.M.; Batenburg, S.J.; Mander, L. Aberrant Classopollis pollen reveals evidence for unreduced (2n) pollen in the conifer family Cheirolepidiaceae during the Triassic-Jurassic transition. Proc. Biol. Sci. 2013, 280, 20131708. [CrossRef] [PubMed]

14. Xue., Z.; Liu, P.; Liu, M. Cytological mechanism of 2n pollen formation in Chinese jujube (Ziziphus jujuba Mill.'Linglingzao'). Euphytica 2011, 182, 231-238. [CrossRef]

15. Sugiura, A.; Ohkuma, T.; Choi, Y.A.; Tao, R. Production of nonaploid $(2 \mathrm{n}=9 \mathrm{x})$ Japanese persimmons (Diospyros kaki) by pollination with unreduced $(2 \mathrm{n}=6 \mathrm{x})$ pollen and embryo rescue culture. J. Am. Soc. Hortic. Sci. 2000, 125, 609-614.

16. Yang, J.; Yao, P.; Li, Y.; Mo, J.; Wang, J.; Kang, X. Induction of 2n pollen with colchicine during microsporogenesis in Eucalyptus. Euphytica 2016, 210, 69-78. [CrossRef]

17. Mao, Y.K.; Zhang, P.D.; Shi, L.; Dong, C.B.; Suo, Y.J.; Kang, X.Y. The optimum conditions for inducing 2n pollen chromosome doubling by high temperature in Eucommia ulmoides. J. Beijing For. Univ. 2013, 35, 53-58.

18. Cheng, J.; Li, Y.; Wang, Y.; Jiang, J.; Wang, Q.; Feng, D.; Hu, J. Pollen chromosome doubling of Ginkgo biloba induced by colchicines. J. Beijing For. Univ. 2006, 28, 15.

19. Kang, X.; Zhu, Z.; Zhang, Z. Suitable period of high temperature treatment of $2 \mathrm{n}$ pollen of Populus tomentosa $\times$ P. bolleana. J. Beijing For. Univ. 1999, 22, 1-4. 
20. Yang, J.; Kang, X.Y. Microsporogenesis and flower development in Eucalyptus urophylla $\times$ E. tereticornis. Breed. Sci. 2015, 65, 138-144. [CrossRef] [PubMed]

21. Yu, F.; Wang, B.H.; Feng, S.P.; Wang, J.Y.; Li, W.G.; Wu, Y.T. Development, characterization, and cross-species/genera transferability of SSR markers for rubber tree (Hevea brasiliensis). Plant Cell Rep. 2011, 30, 335-344. [CrossRef] [PubMed]

22. Li, D.J.; Xia, Z.; Deng, Z.; Liu, X.; Dong, J.; Feng, F. Development, characterization, genetic diversity and cross-species/genera transferability of ILP markers in rubber tree (Hevea brasiliensis). Genes Genom. 2013, 35, 719-731. [CrossRef]

23. Lau, N.-S.; Makita, Y.; Kawashima, M.; Taylor, T.D.; Kondo, S.; Othman, A.S.; Shu-Chien, A.C.; Matsui, M. The rubber tree genome shows expansion of gene family associated with rubber biosynthesis. Sci. Rep. 2016, 6, 28594. [CrossRef] [PubMed]

24. Wang, J.; Li, D.L.; Kang, X.Y. Induction of unreduced megaspores with high temperature during megasporogenesis in Populus. Ann. For. Sci. 2012, 69, 59-67. [CrossRef]

25. Lu, M.; Zhang, P.D.; Kang, X.Y. Induction of $2 \mathrm{n}$ female gametes in Populus adenopoda Maxim by high temperature exposure during female gametophyte development. Breed. Sci. 2013, 63, 96-103. [CrossRef] [PubMed]

26. Li, Y.; Wang, Y.; Wang, P.; Yang, J.; Kang, X. Induction of unreduced megaspores in Eucommia ulmoides by high temperature treatment during megasporogenesis. Euphytica 2016, 212, 515-524. [CrossRef]

27. Zhang, X.Z.; Liu, G.J.; Yan, L.Y.; Zhao, Y.B.; Chang, R.F.; Wu, L.P. Creating triploid germplasm via induced 2n pollen in Capsicum annuum L. J. Hortic. Sci. Biotechnol. 2002, 78, 84-88. [CrossRef]

28. Zhang, L.; Wang, J.; Suo, Y.J.; Kang, X.Y. Pollen chromosome doubling under high temperature in Populusalba. L. J. Nucl. Agric. Sci. 2010, 24, 1158-1165.

29. Wang, C.; Lentini, Z.; Tabares, E.; Quintero, M.; Ceballos, H.; Dedicova, B.; Sautter, C.; Olaya, C.; Zhang, P. Microsporogenesis and pollen formation in cassava. Biol. Plant. 2011, 55, 469-478. [CrossRef]

30. Wyatt, R. Inflorescence architecture: How flower number, arrangement, and phenology affect pollination and fruit-set. Am. J. Bot. 1982, 69, 585-594. [CrossRef]

31. Orjeda, G.; Freyre, R.; Iwanaga, M. Production of 2 n pollen in diploid Ipomoea trifida, a putative wild ancestor of sweet potato. J. Hered. 1990, 81, 462-467. [CrossRef]

32. Lopez-Lavalle, L.A.B.; Orjeda, G. Occurrence and cytological mechanism of $2 \mathrm{n}$ pollen formation in a tetraploid accession of Ipomoea batatas (sweet potato). J. Hered. 2002, 93, 185-192. [CrossRef]

33. Okazaki, K.; Kurimoto, K.; Miyajima, I.; Enami, A.; Mizuochi, H.; Matsumoto, Y.; Ohya, H. Induction of 2n pollen in tulips by arresting meiotic process with nitrous oxide gas. Euphytica 2005, 143, 101-114. [CrossRef]

34. Akutsu, M.; Kitamura, S.; Toda, R.; Miyajima, I.; Okazaki, K. Production of 2n pollen of Asiatic hybrid lilies by nitrous oxide treatment. Euphytica 2007, 155, 143-152. [CrossRef]

35. Ramsey, J. Unreduced gametes and neopolyploids in natural populations of Achillea borealis (Asteraceae). Heredity 2007, 98, 143-150. [CrossRef] [PubMed]

36. Priyadarshan, P.M.; Gonçalves, P.S.; Omokhafe, K.O. Breeding Hevea Rubber. Breeding Plantation Tree Crops: Tropical Species; Springer: New York, NY, USA, 2009; pp. 469-522.

37. Wu, C.T.; Li, W.G.; Gao, X.S.; Zhang, X.F.; Zhang, W.S. Problems in rubber tree breeding in China and their counter measures. Acta Agric. Jiangxi 2009, 21, 74-77.

38. Nayanakantha, N.M.C.; Tian, L. Hevea's tissue culture outlook: Past, now and future. World Trop. Agric. Inf. 2010, 10, 1-5.

39. Peng, S.Q.; Chen, S.C. Advances in molecular biology of rubber tree (Hevea brasiliensis). Lett. Biotechnol. 2001, 12, 314-317.

40. Zheng, X.; Zeng, X.; Chen, X.; Yang, G. A further report on induction and cytological studies on polyploid mutants of Hevea (I). Chin. J. Trop. Crops 1980, 1, 27-31.

41. Zheng, X.; Zeng, X.; Chen, X.; Yang, G. A further report on induction and cytological studies on polyploid mutants of Hevea (II). Chin. J. Trop. Crops 1981, 2, 1-9.

42. Tan, D.; Zhuang, N.; Huang, H. Advances in ploidy breeding of Hevea brasiliensis. Chin. J. Trop. Agric. 2004, $24,58-64$.

43. Harihar, G.; Yeang, H.Y. The low fruit set that follows conventional hand pollination in Hevea brasiliensis: Insufficiency of pollen as a cause. J. Rubber Res. Inst. Malaya 1984, 32, 20-29. 
44. Olapade, E.O.; Omkhafe, K.O. Hand pollination of Hevea brasiliensis in Nigeria (1984-1990). Comparison with open pollinated field data. J. Rubber Res. Inst. Sri Lanka 1990, 70, 27-34.

45. Kang, X.Y.; Zhu, Z.T. A study on the 2 n pollen vitality and germinant characteristics of white poplars. Acta Bot. Yunnanica 1997, 19, 402-406.

46. Li, Y.H.; Kang, X.Y.; Wang, S.D.; Zhang, Z.H.; Chen, H.W. Triploid induction in Populus alba $\times$ P. glandulosa by chromosome doubling of female gametes. Silvae Genet. 2008, 57, 37-40.

(C) 2017 by the authors. Licensee MDPI, Basel, Switzerland. This article is an open access article distributed under the terms and conditions of the Creative Commons Attribution (CC BY) license (http:/ / creativecommons.org/licenses/by/4.0/). 